\title{
The Effect of Mobile Tour Guide Platform on the Promotion of Xi'an in the Background of Wisdom Tour
}

\author{
Xiaoning Dou ${ }^{1}$, Jing Zhao ${ }^{2}$ and Kewei Lei ${ }^{3}$ \\ (1.2.3 Xi'an Eurasian College, Xi'an China 710065, ) \\ 825566508@qq.com; 1123389851@qq.com; 17375732@qq.com
}

Keywords: Wisdom Tour; Xi'an; Mobile phone tour platform

\begin{abstract}
According to the analysis of the great function and powerful advantage of the mobile tour guide platform in the current tourism development, this paper points out that the mobile tour guide platform is a powerful way to promote the tourist industry in Xi'an into Wisdom Tourism. It is a good opportunity to boom Xi'an's economic.
\end{abstract}

\section{Introduction}

\section{An Overview of Wisdom Tourism}

Wisdom Tour is also known as intelligent tour. It uses new technologies, such as cloud computing, Internet of things and other new technologies, to promote various tourist information to people. Specifically, the Internet system/mobile Internet system could perceives relevant information actively and post it on website in real time by using a portable devices. And then, multiple information, which includes tourism resources, tourism economy, tourism events, tourists actives and tourists, will be published online in time to help people knowledge those information, arrange a travel plan and make an adjustment. This technology is really smart on sourcing different tourism information and the convenience on sourcing and using different tourist information.

Xi'an is the bridgehead of the Silk Road Economic Zone and in-band tourism resources in the province. This position is considerable success to local economic. As local citizens, it is our responsibilities to consider about how to boom local economy in the situation of Wisdom Tourism and highly developed Information.

\section{Development Background of Mobile Phone Tour Guide Platform}

With the popularity of smart phones and $4 \mathrm{G}$ eras, mobile phones play an increasingly important role in people's lives. Additionally, tourism has become a way of people's life gradually. It makes "Wisdom Tourism" popular as well. This tendency makes us to think about How to connect customers and smart phones? Thus, visitors can achieve the tour guide function, consumer features and interactive features of tourists through the phone quickly and easily - The application of mobile phone tour platform is produced.

The tour platform can integrate external tourism information. The external information includes the tourist area traffic, accommodation, ticketing, commentary, supporting facilities and complaints. Visitors can overview the introduction of scenic spots efficiently and figure out what they need. The tour platform users can get connections from other visitors and establish good interactive with them. While users could have electronic consumption, fast ticket purchasing, rapid settlement, rapid admission so on by using tour platform; It is significant to reduce the blindness of choosing destinations and increase various methods to select final travelling destination for tourists. The whole process of travelling seems more sensible and knowledgeable.

At present, the vast majority of developed countries and regions have built an integrated tourism information application system, which covers the elements of food, housing, transportation, travel, shopping, and entertainment. In contrast, China still has a big gap compare to those countries and regions.

Integrated Information Application System for Tourism Destination is comparatives useful. On the one hand, it can understand tourists' personal characteristics and demand preference cleanly. It can also analyze and subdivide the tourists' market, which will undoubtedly have a positive effect 
on tourist sustainability, which has a far-reaching significance.; On the other hand, with the development of integrated destination information system, it is very convenient and efficient to provide a full range of tourism-related information. There is great convenience and security for tourists with the function of set query, search, booking in one system gradually.

The platform of mobile phone tour guides can better reflect the characteristics of modern service industry by improving the technical content of tourism industry, increasing the value-added service capability of tourism products, optimizing the structure of talented people and enhancing the tourist experience, so as to build the people's satisfaction. Modern service industry requirements, and ultimately boost economic development in Xi'an to achieve the purpose.

\section{Mobile Phone Tour Platform Overall Idea}

The overall idea of the mobile phone tour platform is to serve the tourists through the Internet, the IOT (Internet of Things, the communication network platform and other advanced information technologies.

First of all, it will provide tourists with various tourism-related information by using audio-visual services mainly, such as weather, transportation, accommodation, food, shopping, entertainment and other information. It could also make special personal tourism plan by collecting tourists' preferences.

Second, the mobile phone tour platform could integrate various tourism elements to realize the function of querying information of peripheral of tourists' location, restaurants, shopping and others. It will create a digital scenic spots with the diversity of smart travelling city.

Finally, the system will become an electronic platform and interactive communication platform, which includes ticket booking, information sharing and information exchange.

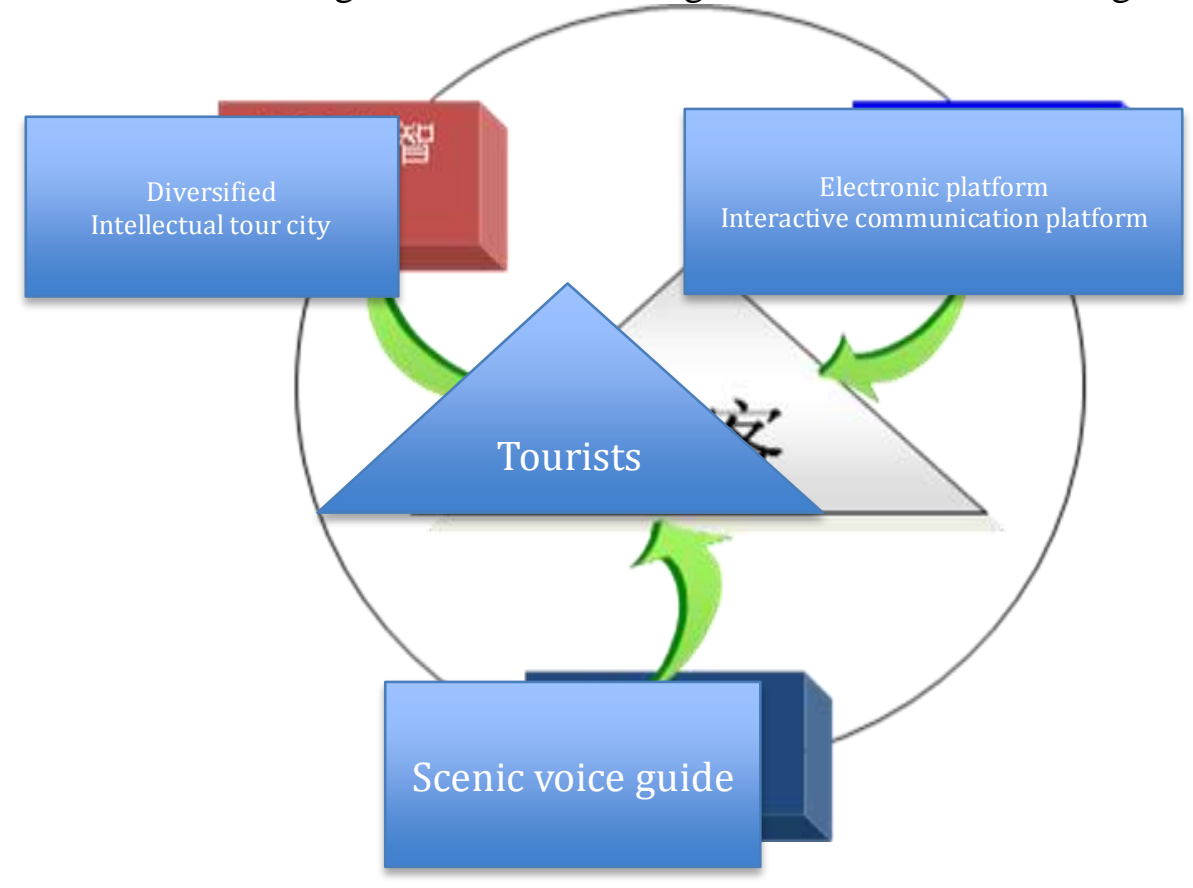

Figure 1. The overall idea of mobile phone tour platform

\section{The Overall Service Ideas of Mobile Phone Tour Platform}

The entire service is based on IP network. It includes network diagram (middle cloud services),

The whole system provides three types of users with information services:

Providing the information platform service for the scenic spot administrator;

Providing various types of information services for the mobile terminal users in travel;

Providing various types of information services for PC terminal users who are not traveling.

\section{The Overall Structure of Mobile Phone Tour Platform}

The whole system software design is divided into several parts: perception layer, data layer, unified platform and application layer. It is operated and managed by SOA governance framework. And it can be connected with existing external systems effectively. Through this application 
architecture, the system is constructed and optimized from the perspective of "service" to achieve business function such as business functions reuse, flexible process combination.

To screen and integrate the mass existing scenic tourist information. And it will be demonstrated the way of tourists in logic of thinking and habits.

To link travel information, in accordance with the needs of visitors, to show, to provide visitors with the overall information.

To create tourism information and tourist interaction through the portal, so that visitors are not only information obtainers, but also an information contributor and information disseminators. Mobile tour guide portal information data system is created based on the Wisdom Tourism cloud computing center. And then, large amount of tourism information is acquired from local counties' institutes and enterprises directly through the data exchange center. According to the needs of tourists, travellers could view information of the citylcounties, scenic spots, tourism-related service units and other advisory information.

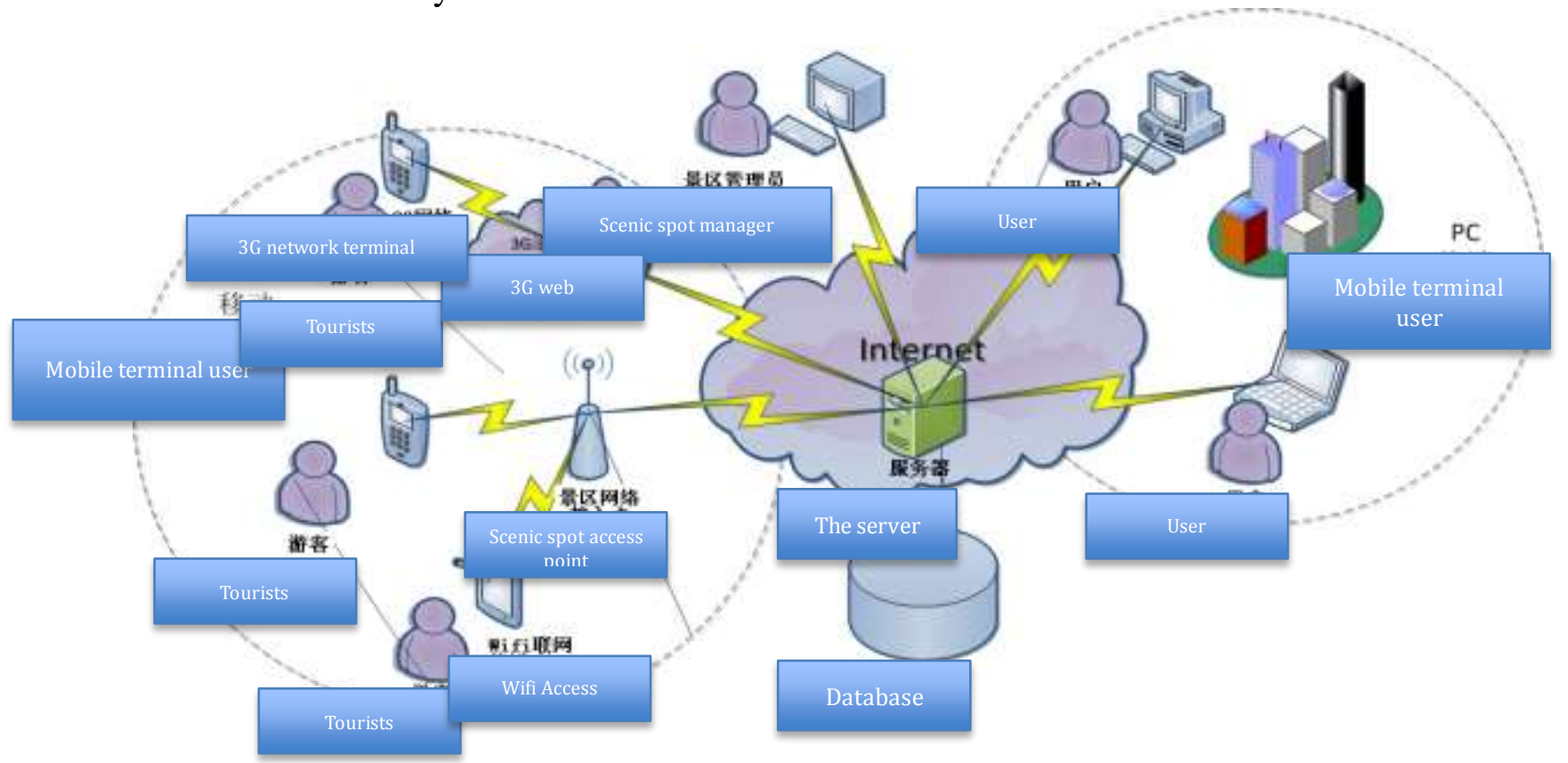

Figure 2. Overall service concept map

\section{Smart Terminal of Mobile Phone Guide APP}

A smartphone terminal can input or output the location of data from a smartphone system, with which users interact by using their smart phones. The ultra-portable of Smart phones and tablet provides a hardware support to Wisdom Tourism.

The smart terminal Mobile Guide APP system mainly includes following functions:

The main interface shows the main service button icons. It includes attractions, tourist routes, food service, hotels choice, tickets purchasing, specialty shopping, leisure and personal service centers.

Attractions: To provide three-dimensional real attractions display, scenic ticket booking and map navigation.

Hotel: To provide hotel information around user's location, and to provide each room's three-dimensional virtual display for the user to choose and reserve.

Routs: To provide tourists' routes inquiries, reservations, routs introduction, routs map and drop by tourist attractions, which is demonstrated by three-dimensional virtual display.

Food: The system will also provide restaurants' characteristics with three-dimensional demonstration. Additionally, the system could provide GPS for users with three ways, which are self-driving, public transport, and walking. Users could make a dinner reservation via use the system.

Entertainments: To provide leisure and entertainment around the users' location.

Weather Forecast: To provide next 5 days local weather forecast to users. 
Requirement announcement: Users could public their personalized travel needs via mobile. According to Wisdom Tourism cloud platform, tourism providers could provide users personalized custom services.

Mobile phone electronic ticket system.

\section{The function of Mobile Phone Guide Platform in Economic Development}

\section{Convenience of Receiving Information}

It is easy to receive information by using potable end-device, which demonstrates information clearly. As a result of better access to information visitors can understand the attractions before the tour and in-depth information after the tour, so that visitors can have a profound understanding of the meaning of attractions.

The Authoritativeness and Timeliness of Information.

Web site and tourist enterprises are in close cooperation. It would make the information of attractions more authoritative and timely-based.

Rich "After the Tour" Service

Users could review their trips and obtain continual pleasure. They can review photos, write down their travel feelings and experience and share with others.

To Integrate Tourism Resources and Providing a Full Range of Information Services

The Mobile travel platform could make cooperation with every attraction. It can post its integrated trip information to tourists. Relevantly, it will report tourists' location and scenic spots' ranking to Scenic Spot Management Office. It will be benefit to the office to make a strategic decision.

To Gradually form Digital Tourism Platform, Based on Cloud Services.

Due to the openness of the system, it will not only offer services but also obtain relevant travel information and enrich travel database at low cost, and finally achieving the object of building a digital platform.

\section{Mobile Information Service}

It is difficult to for tourists to obtain sufficient information before their trip. They need to know the dynamic local travel information, and then tourists can avoid every uncertainty during the trip. The Internet offers the possibility to users to obtain information at any time.

The Voice Guide mobile ends can offer visitors a comprehensive tourism information service.

\section{Mobile Location Services}

The biggest obstacle for tourists is the lack of direction sense when tourists go to a strange place. However, tourists could use mobile location service, which acquires tourists' location and GPS service by using Mobile phone.

In conclusion, if $\mathrm{Xi}$ 'an want to stand out in the Wisdom Tourism construction to lay its economic status, it has to break the industry patterns. It has to use mobile guide platform to promote the development of Wisdom Tourism and to enhance its comprehensive competitiveness.

\section{Acknowledgements}

Fund project: Project of education department of shaanxi province: Research on the promotion of exhibition tourism in xi 'an city under the background of "Internet plus"(17JK1031); The "One Belt And One Road" strategy for the evolution and application of the tourism market in shaanxi province(17JK1036)

\section{Reference}

[1] Li Yunpeng, Chao Xi, Shen Huayu. Wisdom Tourism: from tourism information to tourism intelligence [M]. Beijing: China Tourism Press, 2013: 1

[2] LIU Jun-lin, FAN Yun-feng. Composition, Value and Development Trend of Wisdom Tourism [J] .Chongqing Social Sciences, 2011 (10): 121-124

[3] Zhu Zhu, Zhang Xin. Discussion on the Construction of Wisdom Tourist Perception System 
and Management Platform [J]. Journal of Jiangsu University: Social Science Edition, 2011,13 (6): $97-100$

[4] SONG Rui, DI Xiao-feng, LI Xin. Design and Implementation of Mobile Guide Service Platform [J]. Journal of Computer Applications, 2012, (32): 217-220

[5] Liu Yufeng, He Yajun, Li Hu. The discussion of the application of virtual reality technology in Tourism Information Services [J]. Microcomputer Applications, 2011,32 (1): 75-80

[6] Zhao Yuan, Zhao Jun. Electronic guide system based on mobile GIS and smartphone development and key technologies [J]. Digital Technology and Applications, 2011: 51-52

[7] Q. Baire, C. Bruyninx,J. Legrand, E. Pottiaux, W. Aerts, P. Defraigne, N. Bergeot,J. Influence of different GPS receiver antenna calibration models on geodetic positioning[J]. GPS Solutions . 2014 (4)

[8] Pan Li, Xiaohong Zhang. Integrating GPS and GLONASS to accelerate convergence and initialization times of precise point positioning[J]. GPS Solutions . 2014 (3)

[9] Jae-Young Lee, Hyung-Min Park, Seok-Han Lee, Soon-Ho Shin, Tae-Eun Kim, Jong-Soo Choi. Design and implementation of an augmented reality system using gaze interaction[J]. Multimedia Tools and Applications . 2014 (2)

[10] Damianos Gavalas,Michael Kenteris. A web-based pervasive recommendation system for mobile tourist guides. Personal and Ubiquitous Computing . 2011 